\title{
Comparative Transcriptomic Analysis of Regenerated Skins Provides Insights into Cutaneous Air-Breathing Formation in Fish
}

\author{
Songqian Huang ${ }^{1,2,+}$, Bing Sun ${ }^{1,+}$, Longfei Huang ${ }^{1,3}$, Lijuan Yang ${ }^{1}$, Chuanshu Liu ${ }^{1}$, Jinli Zhu ${ }^{4}$, Jian Gao ${ }^{1,3, *}$ \\ and Xiaojuan Cao $1,3, * \mathbb{D}$
}

1 Key Lab of Freshwater Animal Breeding, Ministry of Agriculture, College of Fisheries, Huazhong Agricultural University, Wuhan 430070, China; huangsongqian0115@gmail.com (S.H.); sunbing931014@163.com (B.S.); 15207173315@163.com (L.H.); atyanglijuan@163.com (L.Y.); liuchuanshu2021@163.com (C.L.)

2 Department of Aquatic Bioscience, Graduate School of Agricultural and Life Sciences, The University of Tokyo, Bunkyo-ku, Tokyo 113-8657, Japan

3 Engineering Research Center of Green Development for Conventional Aquatic Biological Industry in the Yangtze River Economic Belt, Ministry of Education/Hubei Provincial Engineering Laboratory for Pond Aquaculture, College of Fisheries, Huazhong Agricultural University, Wuhan 430070, China

4 National Demonstration Center for Experimental Aquaculture Education, Huazhong Agricultural University, Wuhan 430070, China; zhujinli1898@163.com

* Correspondence: gaojian@mail.hzau.edu.cn (J.G.); caoxiaojuan@mail.hzau.edu.cn (X.C.); Tel.: +86-027-872-82-113 (X.C.)

check for updates

Citation: Huang, S.; Sun, B.; Huang, L.; Yang, L.; Liu, C.; Zhu, J.; Gao, J.; Cao, X. Comparative Transcriptomic Analysis of Regenerated Skins Provides Insights into Cutaneous Air-Breathing Formation in Fish. Biology 2021, 10, 1294. https:// doi.org/10.3390/biology10121294

Academic Editor: Willem B. Van Muiswinkel

Received: 5 November 2021

Accepted: 7 December 2021

Published: 8 December 2021

Publisher's Note: MDPI stays neutral with regard to jurisdictional claims in published maps and institutional affiliations.

Copyright: (c) 2021 by the authors. Licensee MDPI, Basel, Switzerland. This article is an open access article distributed under the terms and conditions of the Creative Commons Attribution (CC BY) license (https:// creativecommons.org/licenses/by/ $4.0 /)$.
+ means co-first author.

Simple Summary: Cutaneous air-breathing is one of the air-breathing patterns in bimodal respiration fishes, while little is known about its underlying formation mechanisms. The skin regeneration of loach (Misgurnus anguillicaudatus, a cutaneous air-breathing fish) and yellow catfish (Pelteobagrus fulvidraco, a water-breathing fish) were first investigated through morphological and histological observations. Then, the original skins (OS: MOS, POS) and regenerated skins (RS: MRS, PRS) when their capillaries were the most abundant during healing, of the two fish species were collected for high-throughput RNA-seq. A total of 56,054 unigenes and 53,731 unigenes were assembled in loach and yellow catfish, respectively. A total of 640 (460 up- and 180 down-regulated) and 4446 (2340 upand 2106 down-regulated) differentially expressed genes (DEGs) were respectively observed in RS/OS of loach and yellow catfish. Subsequently, the two DEG datasets were clustered in GO, KOG, and KEGG databases, and further analyzed by comparison and screening. Consequently, tens of genes and thirteen key pathways were targeted, indicating that these genes and pathways had strong ties to cutaneous skin air-breathing in loach. This study provides new insights into the formation mechanism of cutaneous air-breathing and also offers a substantial contribution to the gene expression profiles of skin regeneration in fish.

Abstract: Cutaneous air-breathing is one of the air-breathing patterns in bimodal respiration fishes, while little is known about its underlying formation mechanisms. Here, we first investigated the skin regeneration of loach (Misgurnus anguillicaudatus, a cutaneous air-breathing fish) and yellow catfish (Pelteobagrus fulvidraco, a water-breathing fish) through morphological and histological observations. Then, the original skins (OS: MOS, POS) and regenerated skins (RS: MRS, PRS) when their capillaries were the most abundant (the structural foundation of air-breathing in fish) during healing, of the two fish species were collected for high-throughput RNA-seq. A total of 56,054 unigenes and 53,731 unigenes were assembled in loach and yellow catfish, respectively. A total of 640 (460 up- and 180 down-regulated) and 4446 (2340 up- and 2106 down-regulated) differentially expressed genes (DEGs) were respectively observed in RS/OS of loach and yellow catfish. Subsequently, the two DEG datasets were clustered in GO, KOG and KEGG databases, and further analyzed by comparison and screening. Consequently, tens of genes and thirteen key pathways were targeted, indicating that these genes and pathways had strong ties to cutaneous skin air-breathing in loach. This study 
provides new insights into the formation mechanism of cutaneous air-breathing and also offers a substantial contribution to the gene expression profiles of skin regeneration in fish.

Keywords: cutaneous air-breathing; skin regeneration; comparative transcriptome; Misgurnus anguillicaudatus; Pelteobagrus fulvidraco

\section{Introduction}

It is well acknowledged that gill respiration is not the only way for fish to obtain oxygen. So far, about 450 fish species have been reported to perform assistant air-breathing [1]. Air-breathing fish take oxygen from air by using their auxiliary air-breathing organs (ABOs) rich in blood vessels, such as skin, buccal and pharyngeal cavity, swim-bladder, tail fin, as well as digestive tract [2,3]. Research on fish of bimodal respiration mainly focuses on morphology and histology of ABOs, respiratory physiology, and their aquaculture applications [4-6]. It has been found that high capillary vascularization is the histological basis for fish ABOs.

Molecular mechanisms of air-breathing formation in fish are still poorly understood and little literature has been published. A transcriptome analysis of Channa argus involved gill and the suprabranchial chamber (an $\mathrm{ABO}$ ) was performed, and then screened out a batch of genes probably related to the formation of air-breathing, such as vascular endothelial growth factor (vegf) and fibroblast growth factor receptor (fgfr) [7]. The whole genome sequencing, assembly, and annotation of $C$. argus were carried out, expecting to unearth the key genes involved in air-breathing regulation [8]. A comparative transcriptome study of walking catfish Clarias batrachus showed that the hemoglobin gene and angiogenesisrelated genes were obviously up-regulated in its $\mathrm{ABO}$ relative to the gill [9]. In total, 15 key pathways and 25 key genes were identified by a developmental transcriptome analysis, presenting relationship to the formation of intestinal air-breathing in loach (Misgurnus anguillicaudatus) in our previous research [10]. Moreover, after inhibiting the intestinal air-breathing in loach, we mined some potential genes and miRNAs important for maintaining the air-breathing [11,12]. At present, large number of genes and pathways have been proven involved in gas exchange process and vascularization in vertebrate [13-15], but it is rarely reported to attach these genes and pathways to fish air-breathing formation.

Loach M. anguillicaudatus, a small freshwater teleost fish that lives in rice fields and streams, and is widespread in Eurasia [16], can exchange gas both in water via the gill, and in air via intestine and skin $[17,18]$. The skin is considered as an auxiliary respiratory organ in loach, while the attention paid to it primarily lies in the aspects of morphology and histology [19-21]. To satisfy the demand of cutaneous respiration, the main modifications targeted on the skin of loach are as follows: high capillary epithelialization, degenerated scales, and well differentiated cutaneous gland cells. In addition, the middle layer of loach skin epidermis is mainly composed of multi-laminar swollen cells, which serve as a barrier to effectively reduce the moisture loss [22] and avoid dry skin when exposing to air for a long time. Yellow catfish (Pelteobagrus fulvidraco), a small freshwater teleost fish without air-breathing function, shares common niche and diet with the loach [23,24]. In addition, skins of these two fishes are rich in goblet cells, capable of secreting a large amount of mucus, especially under stress, although the skin surface of yellow catfish is lacking tiny scales like the loach $[21,23]$.

In the present study, skin regeneration observations of loach and yellow catfish were first performed by virtue of skin incision, morphological, and histological methods. Next, regenerated skins when their highest vascularization occurred and original skins of the two fishes were collected for RNA-seq and comparative analysis, aiming to investigate the molecular mechanism of cutaneous air-breathing formation in the loach. This study not only provides a novel understanding of the mechanisms of cutaneous air-breathing 
formation, but also offers a substantial contribution to the gene expression profiles of skin regeneration in fish.

\section{Materials and Methods}

\subsection{Fish}

All experimental diploid loach $M$. anguillicaudatus (the average weight and body length were $13.40 \pm 0.51 \mathrm{~g}$ and $11.77 \pm 1.81 \mathrm{~cm}$, respectively) and yellow catfish P. fulvidraco (the average weight and body length were $86.75 \pm 12.85 \mathrm{~g}$ and $17.40 \pm 1.17 \mathrm{~cm}$, respectively) were obtained from the Aquaculture Base of College of Fisheries, Huazhong Agricultural University in Wuhan City, Hubei Province, China. The experimental fish were cultured in recirculating water with temperature of $24-26^{\circ} \mathrm{C}$ and dissolved oxygen of $6.5 \pm 0.7 \mathrm{mg} \cdot \mathrm{L}^{-1}$ and fed three times a day.

\subsection{Cutaneous Air-Breathing Confirmation in Loach}

It is thought that loach can breathe air via its skin, but it has not been confirmed by experiments. Since loach could inhale air through its mouth to posterior intestine conducting accessory respiration, mouth suture method was carried out in loach to restrain intestinal air-breathing, and then the cutaneous air-breathing of the loach was confirmed (Figure S1). Firstly, the mouths of loaches were stitched with surgical sutures (Figure S1a). Then, we placed the loaches in water in a sealed plastic bag (Figure S1b, 2/3 volume was water and $1 / 3$ was nitrogen). After asphyxia by hypoxia, we removed half of the loaches and exposed them to air (Figure S1c,d, the air exposure group), which had neither waterbreathing, nor intestinal air-breathing at this time. The other half of loaches remained in the plastic bag without dissolved oxygen in the water (the control group). The survival rates of loaches were evaluated at $15 \mathrm{~min}$ after air exposure and non-air exposure.

\subsection{Cutaneous Incision and Morphological Observations of Regenerated Skins}

After anesthetized with $100 \mathrm{mg} \cdot \mathrm{L}^{-1}$ tricaine methanesulfonate (MS-222) [11], the skin tissues of $1 \mathrm{~cm}^{2}$ size beneath the dorsal fin of ten loaches were dissected away by virtue of sharp and sterile blades (Figure 1a). After a few minutes of recovery in fresh aerated water, the loaches were held temporarily in an anti-infection tank by adding with $1 \mathrm{mg} \cdot \mathrm{L}^{-1}$ malachite green dye (Sigma-Aldrich, St. Louis, MO, USA), next day the survival fish were returned to the rearing system [25]. Then, the process of loach skin regeneration and development was observed and photographed under the stereomicroscope (Nikon SMZ 1500, Tokyo, Japan) every day, till the wound was completely healed. The identical operation above was entirely applied in yellow catfish simultaneously.

\subsection{Cutaneous Incision and Histological Observations of Regenerated Skins}

According to the morphological observation results of regenerated skins in loach and yellow catfish, the original skin and the regenerated skins of 3rd, 6th, 9th, and 12th day after cutaneous incision (daci) of loach $(n=5)$, and the original skin and the regenerated skins of 2 nd, 4 th, and 6th daci of yellow catfish $(n=5)$ were dissected out for histological observations. The skin tissues were fixed in the Bouin's fixative for $24 \mathrm{~h}$ and then stored in $70 \%$ ethanol. After dehydration in a graded series of ethanol and transparency by xylene, the skin samples were embedded in paraffin and sectioned in serial transverse sections ( $5 \mu \mathrm{m}$ thick), by using a Leica RM 2135 rotary microtome (Leica Ltd., Wetzlar, Germany). Dewaxed serial sections were stained with Delafield's haematoxylin for $24 \mathrm{~h}$, then all samples were dehydrated in graded ethanol and embedded in paraffin wax. Cross sections of $4 \mu \mathrm{m}$ thickness were stained with hematoxylin and eosin (H\&E) to show general histological observations of the regenerated skins of loach and yellow catfish [24]. 
(a)
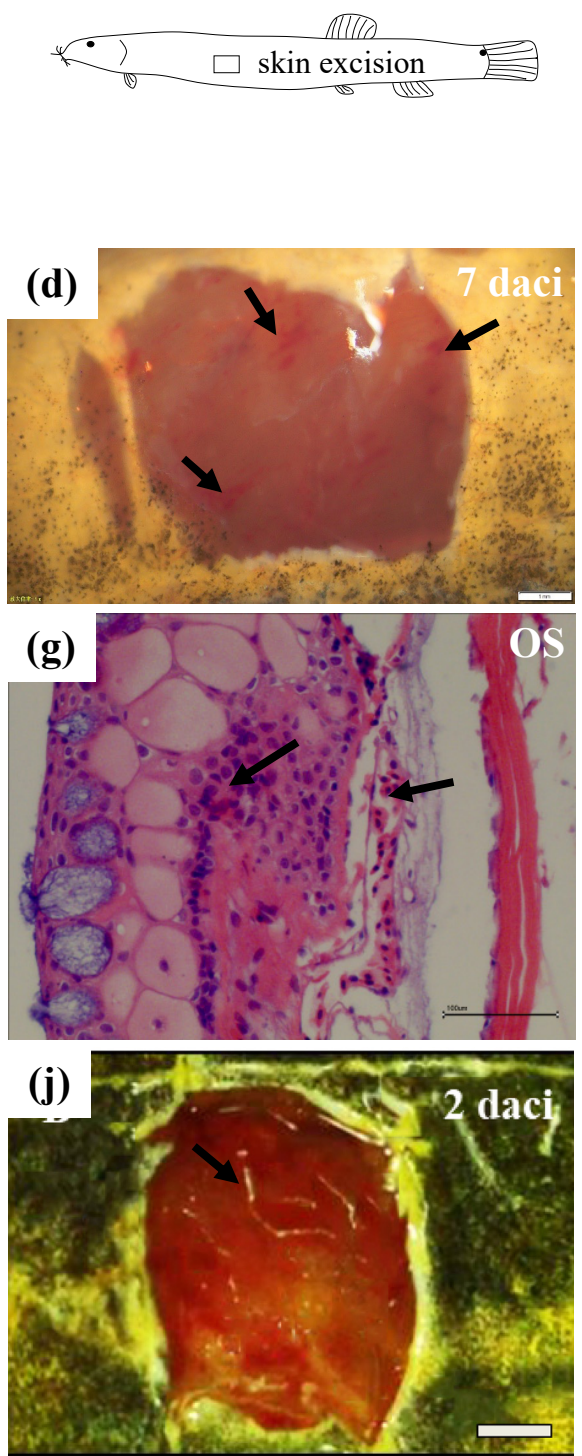

(m)

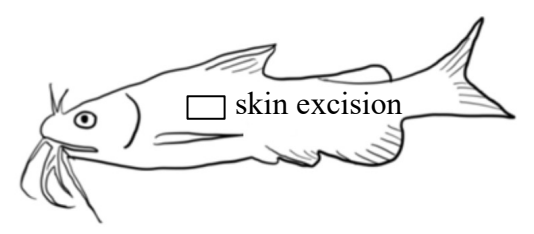

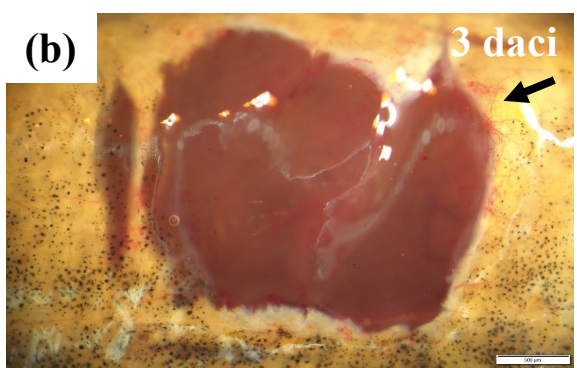
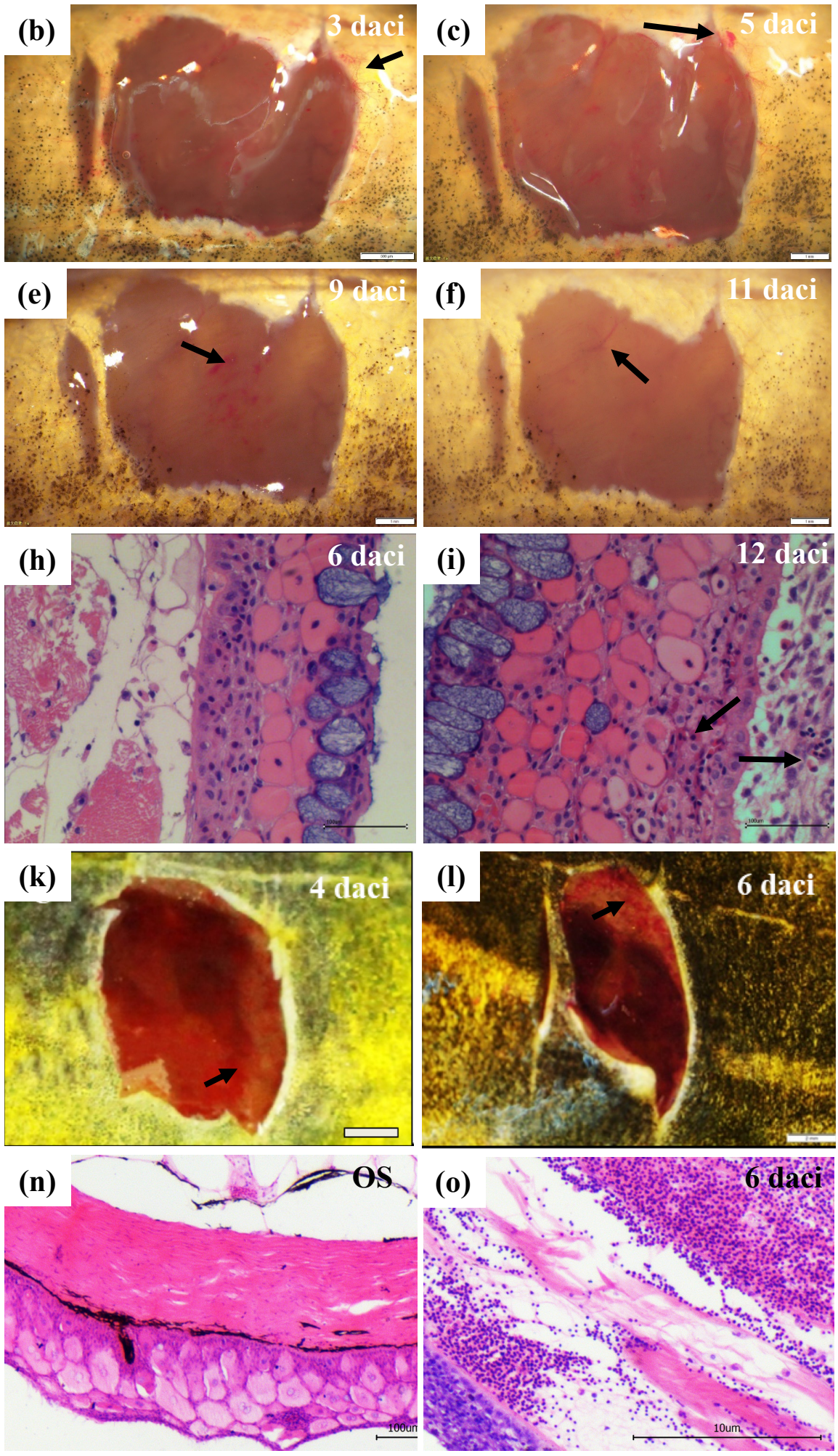

Figure 1. Morphological and histological observations of regenerated skins of loach and yellow catfish. (a) Sketch map of cutaneous incision for morphological observations of regenerated skins. (b-f) Morphologies of regenerated skins of the 3rd, 5th, 7th, 9th, and 11th day after cutaneous incision (daci) of loach. Scale bars indicate $1 \mathrm{~mm}$. (g-i) Histological structures of original skin (OS) and regenerated skins of the 6th and 12th daci of loach. Scale bars indicate $10 \mu \mathrm{M}$. Black arrows show blood vessels. (j-1) Morphologies of regenerated skins of the 2 nd, 4 th, and 6 th daci of yellow catfish. Scale bars indicate $1 \mathrm{~mm}$. (m) Sketch map of cutaneous incision for morphological observations of regenerated skins. (n,o) Histological structures of original skin (OS) and 6th daci regenerated skin in yellow catfish. 


\subsection{RNA Isolation and cDNA Library Constructions}

According to the morphological and histological observations, the optimal sampling time points of the regenerated skins (when cutaneous capillaries were the most abundant during healing, which was the structural foundation of air-breathing in fish) for transcriptome analysis were determined. For loach, the 10th daci regenerated skin (MRS) and the original skin (MOS) on the other side symmetrical along the axis of the body were simultaneously taken, with three sets of parallels. Meanwhile, for yellow catfish, the 5th daci regenerated skin (PRS) and the original skin (POS) on the other side symmetrical along the axis of the body were simultaneously taken, with three sets of parallels.

Total RNA was isolated from the skin tissues according to the manufacturer's protocol. The extracted RNA samples of high qualities were used for the cDNA synthesis. Poly (A) mRNA was isolated by using oligo-dT beads (Qiagen, Redwood City, CA, USA). All mRNA was sheared into short fragments (200 nt) by adding fragmentation buffer. First-strand cDNA was generated using random hexamer-primed reverse transcription, followed by the synthesis of the second-strand cDNA using RNase $\mathrm{H}$ and DNA polymerase I. The cDNA fragments were purified by using a QIAquick PCR extraction kit. These purified fragments were then washed with EB buffer for end reparation poly (A) addition and ligated to sequencing adapters. Following agarose gel electrophoresis and extraction of cDNA from gels, the cDNA fragments $(200 \pm 5 \mathrm{bp})$ were purified and enriched by PCR to construct the cDNA library (PE100). Finally, six cDNA libraries (MOS1, MOS2, MOS3, MRS1, MRS2, and MRS3) were constructed in loach; so did yellow catfish (POS1, POS2, POS3, PRS1, PRS2, and PRS3).

\subsection{Sequencing, De Novo Assembly and Functional Annotation}

The cDNA libraries were sequenced on the Illumina sequencing platform (Illumina HiSeq $^{\text {TM }}$ 2500) using the paired-end technology in a single run. The Illumina GA processing pipeline was used to analyze the image and for base calling. The high-quality sequences were required for de novo assembly analysis. Before assembly, raw sequencing reads were trimmed by removing adapter sequences and low-quality nucleotides using FastQC (version 0.11.5) and Cutadapt (-a, Version 1.9.1). Then, all clean reads of the libraries of same species were jointly assembled into contigs performed by Trinity software (version 2.4.0) [26]. After assembly, contigs longer than 200 bases were used for subsequent analysis. The contigs were connected to access the sequence that could not be extended on either end, and the sequence of the unigene was then produced. Next, the unigenes were further spliced and assembled to obtain maximum length non redundant unigenes using TGICL clustering software (-F, version 2.1). Finally, unigenes were aligned with the NCBI Nr [27], Swiss-Prot [28], GO [29], KOG [30], and KEGG [31] database using Blastx procedure in blast (version 2.2.26) with an E-value $<10^{-5}$. Blast2GO (version 5.2.5) was used to obtain GO annotation of the unigenes based on Blastx hits against the NCBI Nr database. Blastn was used to align the unigenes to the NCBI Nr nucleotide database, retrieving proteins with the highest sequence similarity with the given unigenes, along with their protein functional annotations.

\subsection{Differentially Expressed Gene (DEG) Analysis and Enrichment Analysis}

The mapped fragments were normalized for RNA length according to fragment per kilobase of exon model per million mapped reads (FPKM) for each gene [32], which facilitated the comparison of transcript levels between samples. DEGs between MOS and MRS, and between POS and PRS were identified by the DEG-seq package (R software, version 3.4.0) using the MA-plot-based method with Random Sampling model (MARS) method [33]. DEGs were selected by using the following filter criteria: false discovery rate (FDR) $<0.05$ and the absolute value of $\log _{2} \mathrm{FC}$ (fold change) $>1$, meaning that the expression difference for each DEG in different libraries should be at least two-fold. Furthermore, the enrichment analysis of DEGs was conducted with GO database, and the gene number of each GO term was calculated. The main pathways of biochemical and signal transduction 
significantly associated with DEGs were determined via a KEGG pathway analysis. Finally, the DEGs, which associated with air-breathing and regenerative function, were analyzed in detail.

\subsection{Mining of DEGs Related to Cutaneous Air-Breathing}

After the acquisition of two DEGs settings from loach and yellow catfish, the genes of quite significant differences between the two data settings were specially selected as candidate genes and listed in an Excel sheet. Subsequently, subtractive analysis was performed: the same genes happened to loach and yellow catfish were removed from the candidate genes. The rest DEGs of loach were considered to have tight attachment to cutaneous air-breathing, rather than skin regeneration. Furthermore, tens of potential cutaneous air-breathing formation related genes were selected from the DEGs of loach and validated in different loach skin tissues (including OS and regenerated skins of 3rd, 6th, 9th, and 12th daci) by quantitative PCR (qPCR). The primers were designed based on the assembly gene sequences (Table S1).

\subsection{Validation of Transcriptome Data by $q P C R$}

To examine the reliability of the transcriptome results, six DEGs (fibronectin1 (fn1), integrin $\alpha 5$ (itga5), lysyl oxidase-like 2a (loxl2a), loxl2b, lectin galactoside-binding-like 1 (lgals1), and pleckstrin homology H1 (plekhh1)) and six DEGs (fn1, itga5, loxl2a, chemokine receptor 4 (cxcr4), vegfaa, and transforming growth factor-beta receptor 2 (tgfbr2)) in loach and yellow catfish were, respectively, selected to perform qPCR. Total RNAs isolated from the original and regenerated skins were reverse transcribed to first-strand cDNA using reverse transcriptase (Invitrogen, Waltham, MA, USA). The qPCR was carried out on an iQ5 system (Bio-Rad, Hercules, CA, USA) using SYBR Premix Ex Taq (TaKaRa, Dalian, China), according to the manufacturer's instructions. The primers for these genes were designed manually (Table S1). The reaction mixture $(10 \mu \mathrm{L})$ comprised $2.5 \mu \mathrm{L}$ cDNA (1:4 dilution), $5 \mu \mathrm{L}$ SYBR Premix Ex TaqTM II (TaKaRa), $0.5 \mu \mathrm{L}$ specific forward primer $(10 \mu \mathrm{M}), 0.5 \mu \mathrm{L}$ universal primer $(10 \mu \mathrm{M})$, and $1.5 \mu \mathrm{L}$ water. The reactions were performed in an MJ Opticon ${ }^{\mathrm{TM}}-2$ machine (Bio-Rad, Hercules, CA, USA). The relative expression levels were normalized to the endogenous control gene $\beta$-actin, and calculated by the $2^{-\Delta \Delta \mathrm{Ct}}$ method [34].

\subsection{Statistical Analysis}

All qPCR data were presented as the means of three individual experiments \pm standard deviations. Statistical analysis was conducted by $t$ test using SPSS 19.0 (Michigan Avenue, Chicago, IL, USA). Probability values of $p<0.05$ was considered statistically significant.

\section{Results}

\subsection{Morphological and Histological Observations of Skin Regeneration}

In the experiment of loach cutaneous air-breathing confirmation, after hypoxia treatment, the air-exposed loaches with intestinal air-breathing inhibited had a significant higher survival rate than the control group (Figure S1e), which indicated that there was cutaneous air-breathing in the loach. The epidermal skin fragments were dissected away by surgical operation (Figure 1a). The vascularization of the cutting area edges was obvious on the 3rd daci in loach (Figure 1b). Blood capillaries spread to the whole regeneration area of skin on the 5th daci (Figure 1c). On the 7th daci, the vascularization of the regenerated cutaneous edges reverted to the normal level (Figure 1d). Then, till the 9th daci, the vascularized area of the regenerated skin had been transferred to the central part (Figure 1e). Finally, the vascularization of the regenerated skin on the 11th daci was totally completed (Figure 1f).

Furthermore, the histological observations of skin regeneration were performed in loach. Generally, the capillaries are mostly detected in the loose layer of dermis, a few of which stick to the germinal layer or even extend to the epidermis in the original skin (Figure 1g). During the process of cutaneous regeneration, the epidermal layer of the skin 
appeared completely on 3rd daci, with multi-laminar mucous cells and swollen cells, but without dermis differentiation. On the 6th daci, the muscularis began to separate from the epidermis, with emerge of the dermal loose layer (Figure $1 \mathrm{~h}$ ). The muscular layer and the epidermis layer were remarkably separated on the 9th daci, with rather abundant capillaries permeating in it. Finally, on the 12th daci, the germinal layer showed an obvious structure of single-layered cubic cells or columnar cells, and the capillaries within the loose layer were more than those on the 9th daci, reaching the maximum (Figure 1i). Morphologically and histologically, yellow catfish went through similar skin regeneration process as loach (Figure $1 \mathrm{j}-\mathrm{O}$ ). On the 6th daci, the skin regeneration in yellow catfish was basically completed (Figure 11). No obvious capillaries distributed in the original and regenerated skins of yellow catfish were observed (Figure 1n,o).

\subsection{De Novo Assembly and Functional Annotation}

A total of twelve libraries of original and regenerated skins of loach and yellow catfish were performed by RNA-seq. After cleaning and quality checks, the RNA-seq produced 266.13 million clean reads with a total of $36.07 \mathrm{~Gb}$ for loach, and 291.48 million clean reads with a total of $44.83 \mathrm{~Gb}$ for yellow catfish (Table 1). A total of 56,056 unigenes with a mean length of $991 \mathrm{bp}$ and 53,731 unigenes with a mean length of $1080 \mathrm{bp}$ were, respectively, identified in loach and yellow catfish.

Table 1. Summary of mixed-assembling transcriptome data of loach M. anguillicaudatus and yellow catfish P. fulvidraco.

\begin{tabular}{ccc}
\hline Items & Loach & Yellow Catfish \\
\hline Total length & $36.07 \mathrm{~Gb}$ & $44.83 \mathrm{~Gb}$ \\
Total number of clean reads & $266,126,010$ & $291,478,754$ \\
Total number of unigenes & 56,056 & 53,731 \\
Mean length of unigenes (nt) & 991 & 1080 \\
Total number of N50 & 1922 & 2073 \\
\hline
\end{tabular}

To annotate the sequences of loach and yellow catfish, searches were conducted against five public databases (Nr, SwissProt, KEGG, KOG, and GO) (Figure S2). In total, 32,684 (58.31\%) unigenes of loach and 27,169 (52.43\%) unigenes of yellow catfish were simultaneously annotated in more than one public databases. All unigenes from OSs and RSs of loach and yellow catfish were used for function enrichment and classifications analysis. Together, $42,250(75.37 \%)$ unigenes of loach and 39,676 (73.84\%) unigenes of yellow catfish were both annotated in KOG and grouped into 25 KOG classifications which presented almost identical distribution regularity between loach and yellow catfish, especially the top five items. The largest cluster was the signal transduction mechanisms $(21.62 \%$ unigenes from loach, and $22.20 \%$ unigenes from yellow catfish), and then followed by general function prediction only ( $18.08 \%$ unigenes from loach, and $17.17 \%$ unigenes from yellow catfish), posttranslational modification - protein turnover-chaperones $(8.92 \%$ unigenes from loach, and $8.72 \%$ unigenes from yellow catfish), transcription (5.87\% unigenes from loach, and $6.33 \%$ unigenes from yellow catfish), and intracellular trafficking - secretion-vesicular transport ( $5.13 \%$ unigenes from loach, and $5.66 \%$ unigenes from yellow catfish).

GO analysis of all unigenes showed that a total of 17,008 (30.34\%-loach) and 15,611 (29.05\% - yellow catfish) unigenes were annotated. In detail, cellular process (5891 unigenes from loach and 7946 unigenes from yellow catfish) and single-organism process (5416 unigenes from loach and 7105 unigenes from yellow catfish) represented the majority category of biology process. Cell and cell part represented the majority category of cellular component. Moreover, binding and catalytic activity (4229 unigenes from loach and 5654 unigenes from yellow catfish) represented a high percentage of the molecular function category.

For further identification of the biological pathways in loach and yellow catfish, we mapped all the unigenes to the reference of typical pathways in the KEGG database. 15,929 unigenes $(28.42 \%)$ of loach and 14,372 unigenes $(26.75 \%)$ of yellow catfish were 
matched to 230 and 223 different KEGG pathways, respectively. Among these unigenes, top four enrichment KEGG pathways in loach and yellow catfish were identical including focal adhesion (ko04510, 489 unigenes, top1 in loach; 347 unigenes, top4 in yellow catfish), endocytosis (ko04144, 480 unigenes, top2 in loach; 453 unigenes, top1 in yellow catfish), MAPK signaling pathway (ko04010, 424 unigenes, top3 in loach; 402 unigenes, top2 in yellow catfish) and regulation of actin cytoskeleton (ko04810, 404 unigenes, top4 in loach; 376 unigenes, top3 in yellow catfish).

\subsection{DEG Analysis and Enrichment Analysis}

A total of 640 genes and 4446 genes were significant differentially expressed in the comparisons of RSs and OSs of loach and yellow catfish, respectively (Table S2). There were 460 up- and 180 down-regulated DEGs in regenerated skin in comparison of original skin of loach (Figure 2a). Meanwhile, in the regenerated skin and original skin pairwise comparison of yellow catfish, 2340 up- and 2106 down-regulated DEGs were detected in the regenerated skins of yellow catfish (Figure 2b). A total of 295 and 418 GO items were significantly enriched in the regenerated skin of loach and yellow catfish, respectively (Table S3). Among these GO items, extracellular matrix (GO:0031012), multicellular organismal process (GO:0032501), single-multicellular organism process (GO:0044707), anatomical structure development (GO:0048856), anatomical structure morphogenesis (GO:0009653), and vitamin binding (GO:0019842) were simultaneously annotated as top 20 enrichment GO items in the comparisons of RS and OS in loach and yellow catfish (Figure 3). In addition, 28 and 23 KEGG pathways were enriched among the DEGs in the comparisons of RSs and OSs pertain to loach and yellow catfish, respectively (Figure 4a,b). Among these KEGG pathways, ten KEGG pathways were simultaneously annotated as enriched pathways in both of two fishes. ECM-receptor interaction (ko04512) was annotated as highest enriched pathway in both of loach and yellow catfish. Most of the pathways were annotated to relate to cellular differentiation, proliferation, growth and development, while a few immune-related pathways were also enriched in the regenerated skin, such as bacterial invasion of epithelial cells (ko05100) in loach and staphylococcus aureus infection (ko05150) in yellow catfish.

(a)

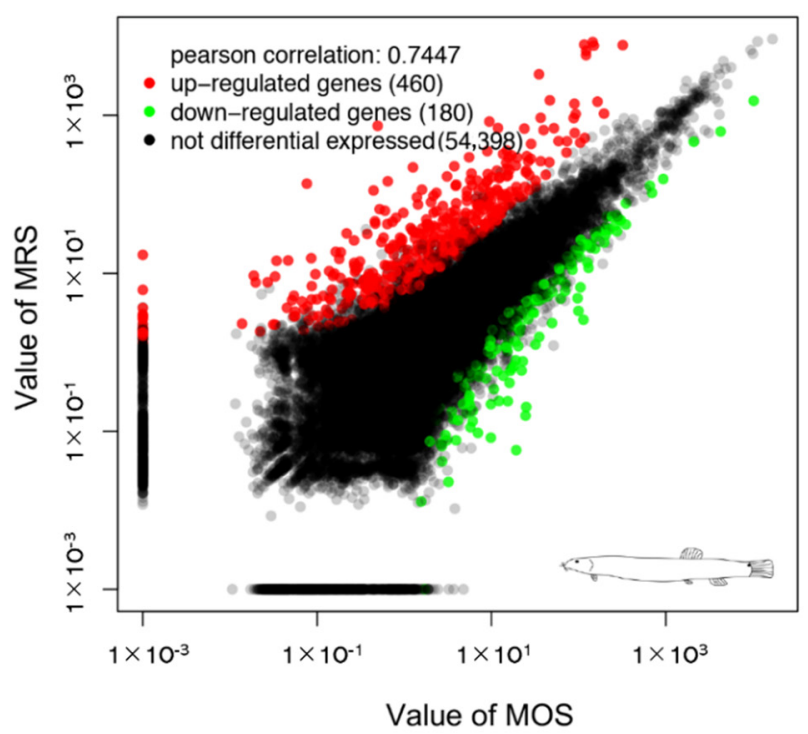

(b)

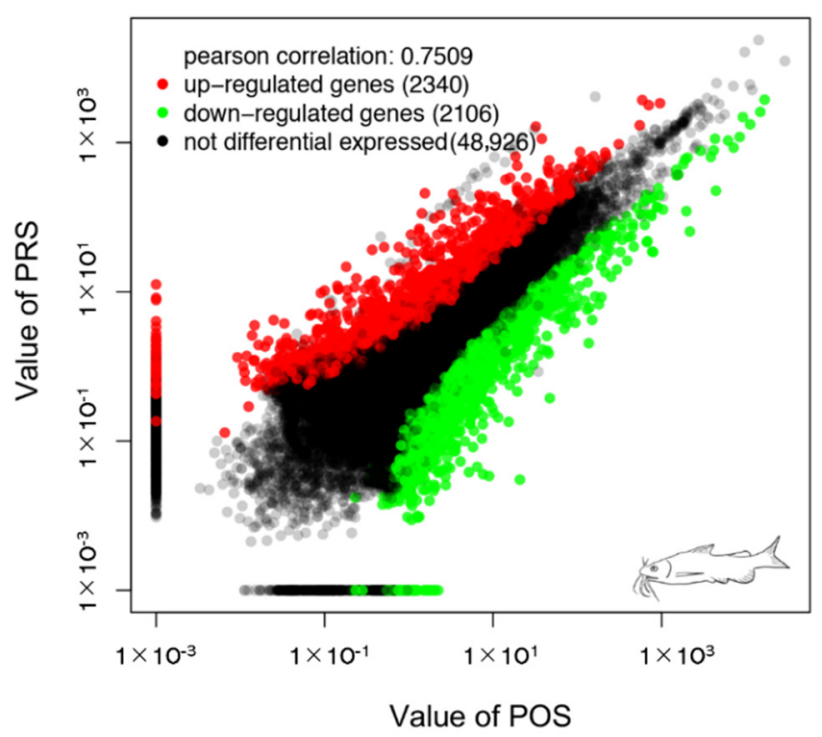

Figure 2. Scatter plot map for genes in comparisons of RS/OS pertain to loach (a) and yellow catfish (b). Each plot represents an individual gene. Red dots show up-regulated genes and green dots down-regulated genes in regenerated skin $\left(\mathrm{FDR}<0.05, \mid \log _{2} \mathrm{FC}(\right.$ fold change $\left.)\right)>1$ ). 
(a)

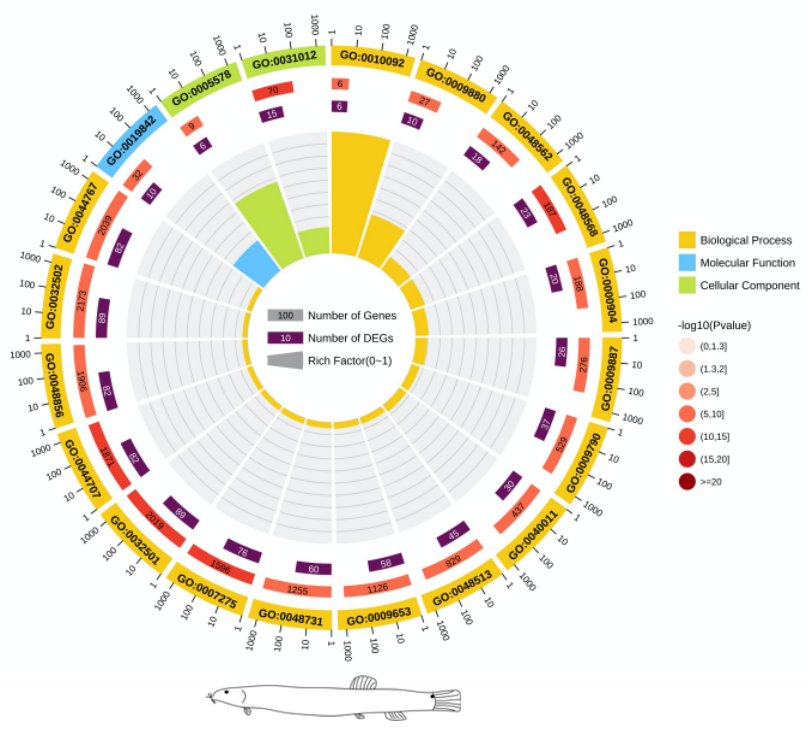

(b)

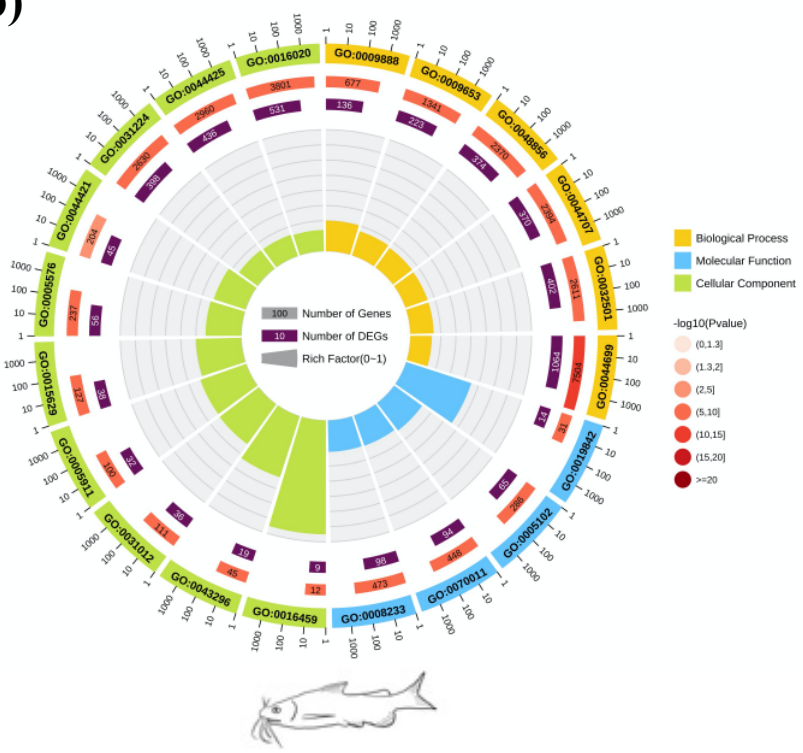

Figure 3. Top 20 of GO classifications enriched in the differentially expressed genes (DEGs) in comparisons of RS/OS pertain to loach (a) and yellow catfish (b). RS: regenerated skins; OS: original skins. The first circle from outside indicates gene number scale and GO items present by GO ids; Second circle indicates gene numbers under each GO item, and third circle shows enriched gene number of DEGs. The concentric circles represent rich factors of each $\mathrm{GO}$ item, which are equal to the ration of gene number of DEGs and background gene number under each GO item.

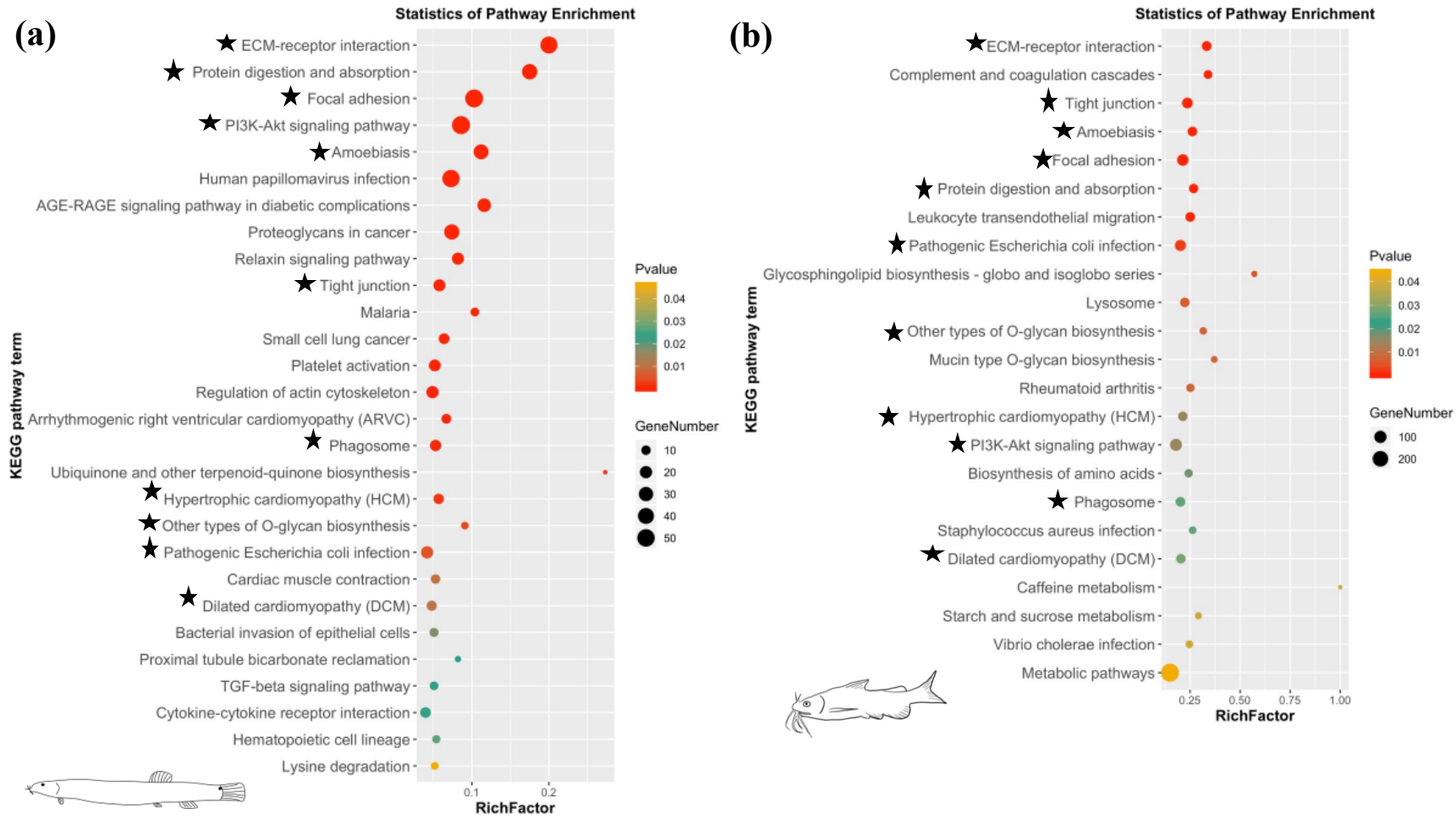

Figure 4. Enrichment of KEGG pathways of differentially expressed genes (DEGs) in the comparisons of RS/OS pertain to loach (a) and yellow catfish (b). RS: regenerated skins; OS: original skins. Black stars indicate common enriched KEGG pathways between loach and yellow catfish. 


\subsection{Mining of Cutaneous Air-Breathing Related Genes in Loach}

Based on the annotation results of all unigenes and the expression performances in loach, 37 potential genes of cutaneous air-breathing formation were targeted (Figure 5). Among these genes, itga11, itga5, thbs 2, thbs1, thbs $4 b$, fn 1 , and $r p s 6 k b 1$ were up-regulated, whereas $f g f r 4, b m p 3$, and igfbp 3 down-regulated upon skin regeneration; thbs $3 a, n g f, p d g f c$, sost, bmp 1, and angptl1 were up-regulated and then down-regulated, while chd and bmp 2 presented opposite expression patterns. In addition, potential genes related to cutaneous airbreathing were excavated in the comparisons of MRS/MOS and PRS/POS. Tens of DEGs, subordinating to thirteen pathways including TGF-beta signaling pathway (ko04350), JakSTAT signaling pathway (ko04630), Wnt signaling pathway (ko04310), vascular smooth muscle contraction (ko04270), were probably related to cutaneous air-breathing formation in loach (Figure S3, Table 2). These genes were most associated with single-organism process (GO:0044699), multicellular organismal process (GO:0032501), developmental process (GO:0032502), single-multicellular organism process (GO:0044707), and anatomical structure development (GO:0048856) (Table S4). Meanwhile, a number of DEGs related to vascular angiogenesis and development in yellow catfish were selected and illustrated in Figure 6 as well, for the purpose of further narrowing the scope of the target genes. Finally, after filtered by the data of yellow catfish, loxl2b, lgals1 and plekhh1 were considered as the key candidate genes involved cutaneous air-breathing formation in loach.

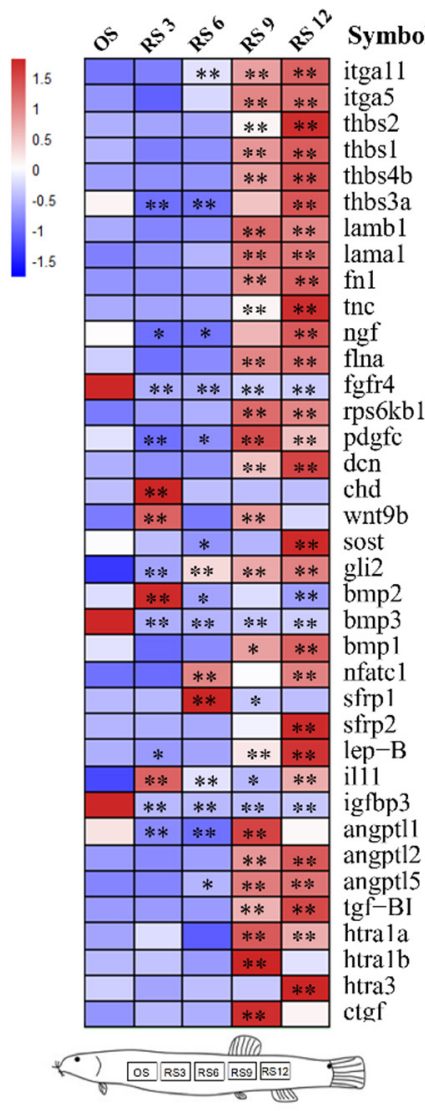

Description
integrin alpha 11
integrin alpha 5
thrombospondin 2
thrombospondin 1
thrombospondin $4 \mathrm{~b}$
thrombospondin 3a
laminin subunit beta 1
laminin subunit alpha 1
fibronectin
tenascin C
nerve growth factor
filamin A
fibroblast growth factor receptor 4
ribosomal protein S6 kinase beta 1
platelet-derived growth factor C
decorin
chordin
wingless-type MMTV integration site family 9
sclerostin
GLI family zinc finger 2
bone morphogenetic protein 2
bone morphogentic protein 3
bone morphogenetic protein 1
nuclear factor of activated T-cells, cytoplasmic 1
secreted frizzled-related protein 1
secreted frizzled-related protein 2
leptin B
interleukin 11
insulin-like growth factor-binding protein 3
angiopoietin-like 1
angiopoietin-like 2
angiopoietin-like 5
lransforming growth factor beta induced
serine protease HTRA1A
serine protease HTRA1B
serine protease HTRA3
connective tissue growth factor

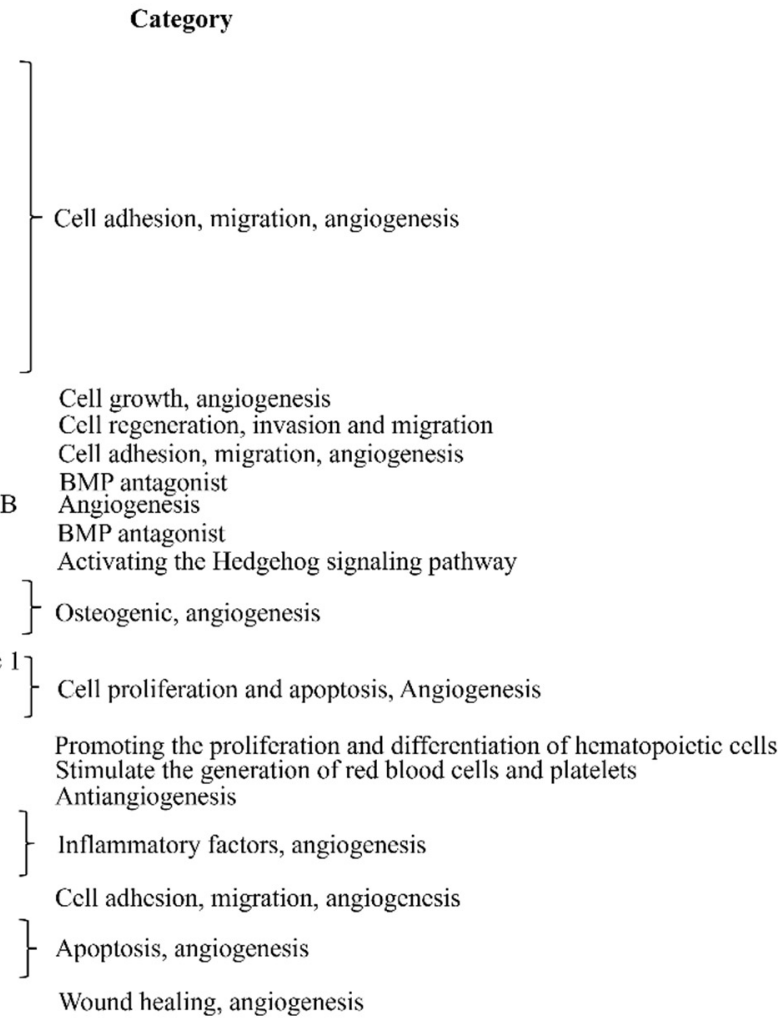

Figure 5. Expression profiles of cutaneous air-breathing formation related genes in regenerated skin of loach. OS: original skin; RS3: regenerated skin of the 3rd day after cutaneous incision (daci). RS6: regenerated skin of the 6th daci. RS9: regenerated skin of the 9 th daci. RS12: regenerated skin of the 12 th daci. ${ }^{*}$ indicates significant difference of gene express level between regenerated skin and original skin $\left({ }^{*} p<0.05,{ }^{* *} p<0.01\right)$. 

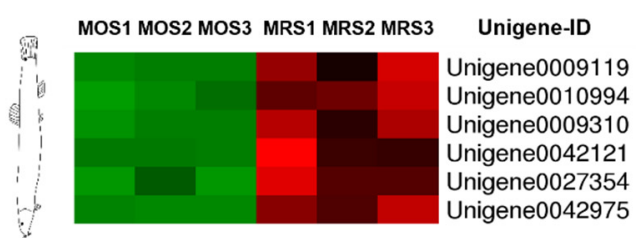

POS1 POS2 POS3 PRS1 PRS2 PRS3

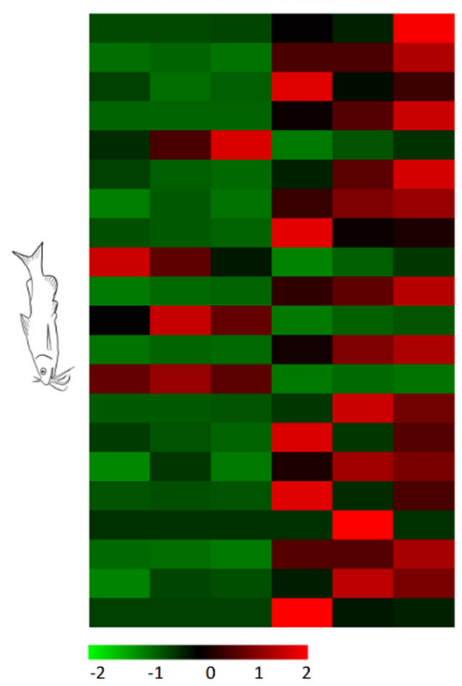

Unigene002489 Unigene0000799 Unigene 0038170 Unigene0002035 Unigene 001383

Unigene 0015134 Unigene0017284 Unigene0017427 Unigene0020194 Unigene0026322 Unigene0026458 Unigene 0032579

Unigene0044008 Unigene0045126 Unigene0052433 Unigene0003813 Unigene0006822 Unigene004980 Unigene0053693 Unigene0021907 Unigene0014779
Symbol

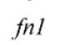

fnl
itga5

loxl2a

$10 x / 2 b$

lgals 1

plekhh1

\section{fnl}

itga5

loxl2a

cxcr4

tbx $5 a$

caxc5 5

$i g f b p 7$

gng2

wht7a

ephb4

parva

vegfaa

hev 2

tgfbr2

hand 2

bdkrb2

$a l b$

plod 3

htr $2 b$

fga
Description

fibronectin

integrin alpha 5

lysyl oxidase homolog 2a

lysyl oxidase homolog $2 b$

beta-galactoside-binding lectin

pleckstrin homology $\mathrm{H} 1$

fibronectin

integrin alpha 5

lysyl oxidase homolog 2 a

chemokine receptor 4

$\mathrm{T}$-box transcription factor $5 \mathrm{a}$

CXXC-type zinc finger protein 5

insulin-like growth factor binding protein 1

guanine nucleotide-binding protein $\mathrm{G}$

protein $\mathrm{Wnt}-7 \mathrm{a}$ subunit gamma 2

ephrin type $-\mathrm{B}$ receptor 4

myosin 6

parvalbumin 2

vascular endothelial growth factor a

hairy/enhancer-of-split related with YRPW

TGF-beta receptor 2

dHAND

B2 bradykinin receptor

serum albumin precursor

Plod3 protein

5-hydroxytryptamine receptor $2 \mathrm{~b}$

Fibrinogen alpha chain
Category

Blood vessel endothelial cell migration

Blood vessel morphogenesis

Blood vessel development

Blood vessel endothelial cell migration

Blood vessel morphogenesi

Regulation of blood vessel size

Figure 6. Expression performances of differentially expressed vascularization-related genes in comparisons of RS/OS pertain to loach and yellow catfish. RS: regenerated skins; OS: original skins.

Table 2. Key pathways associated with cutaneous air-breathing formation in loach

\begin{tabular}{|c|c|c|c|}
\hline ID & Description & $p$ Value & DEGs \\
\hline ko04512 & ECM-receptor interaction & $6.36 \times 10^{-32}$ & $\begin{array}{l}\text { fn1, itga11, itga5, lama1, lamb1, lamc3, thbs1, thbs2, } \\
\text { thbs3a, thbs4b, thc }\end{array}$ \\
\hline ko04510 & Focal adhesion & $1.58 \times 10^{-21}$ & $\begin{array}{l}\text { flna, fn1, itga11, itga5, lama1, lamb1, lamc3, mylpf, } \\
\text { pdgfc, thbs1, thbs2, thbs3a, thbs } 4 b, \ln 2, \text { tnc }\end{array}$ \\
\hline ko04810 & Regulation of actin cytoskeleton & $9.06 \times 10^{-4}$ & itga5, itga11, fn1, pdgfc, mylpf, bdkrb2, fgfr4, tmsb \\
\hline ko04350 & TGF-beta signaling pathway & $2.42 \times 10^{-2}$ & bmp2, rps6kb1, thbs1, dcn, nbl1 \\
\hline ko04630 & Jak-STAT signaling pathway & $3.28 \times 10^{-1}$ & lep- $B$, il11 \\
\hline ko04310 & Wnt signaling pathway & $6.18 \times 10^{-1}$ & nfatc1, sfrp1, serpinf1, sfrp2, fzd2 \\
\hline ko04115 & p53 signaling pathway & $7.47 \times 10^{-1}$ & thbs1, igfbp3 \\
\hline ko04340 & Hedgehog signaling pathway & $8.68 \times 10^{-1}$ & bmp2, ihhb \\
\hline ko04010 & MAPK signaling pathway & $8.82 \times 10^{-1}$ & nfatc1, fgfr $4, f l n a$, cacna $1 b, n g f, c a c n b 4$ \\
\hline ko04270 & Vascular smooth muscle contraction & $9.31 \times 10^{-1}$ & myl6, prkg1 \\
\hline ko04150 & mTOR signaling pathway & $9.60 \times 10^{-1}$ & rps6kb1 \\
\hline ko04012 & ErbB signaling pathway & $9.60 \times 10^{-1}$ & $r p s 6 k b 1$ \\
\hline ko04910 & Insulin signaling pathway & $9.70 \times 10^{-1}$ & $r p s 6 k b 1, f b p 2$ \\
\hline
\end{tabular}

\subsection{Validation of $D E G s$ by $q P C R$}

To validate the gene expression profiles identified by RNA-seq, six DEGs ( $f n 1$, itga5, loxl2a, loxl2b, lgals1, and plekhh1) from loach and six DEGs (fn1, itga5, loxl2a, cxcr4, tgfbr2, and vegfaa) from yellow catfish were chosen to do qPCR analysis. The expression patterns of these genes revealed by qPCR were rather similar to those revealed by RNA-seq (Figure 7a,b). 
(a)

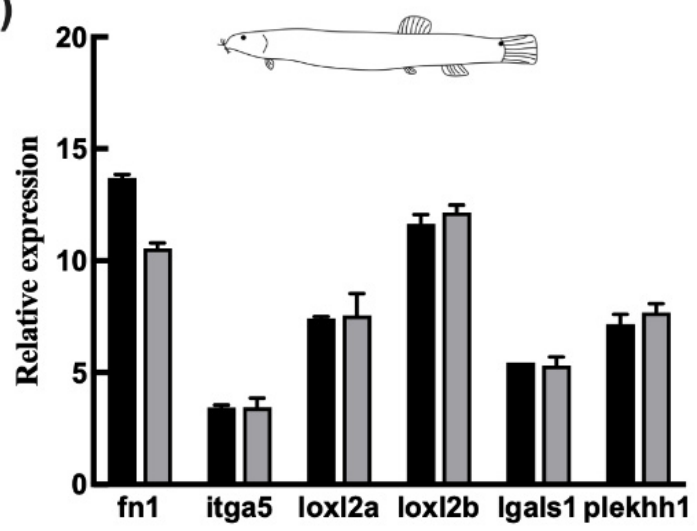

(b)

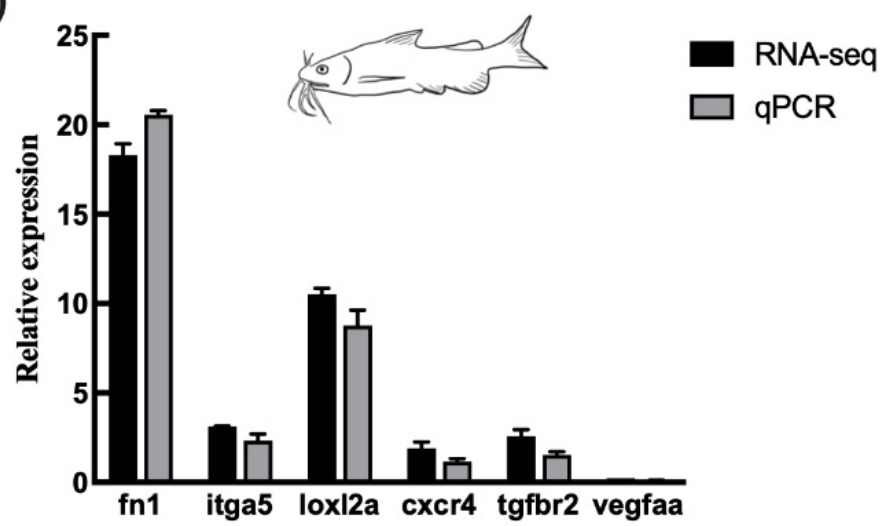

Figure 7. Validation of expression levels of differentially expressed genes (DEGs) in comparisons of RS/OS pertain to loach (a) and yellow catfish (b) between RNA-seq and qPCR. RS: regenerated skins; OS: original skins.

\section{Discussion}

In spite of slight structure differences in fish skins with accessory air-breathing function, there are some characteristics shared: thick skin layer, well differentiated gland cells, highly developed vascular network, capillary epithelialization, and reduced or even disappeared scales [20]. From the perspective of both morphology and histology, the skin of loach was fine modified for the adaption of air-breathing. The middle layer of cutaneous epidermis in air-breathing fish is composed mostly of a variety of epithelial cells with oxygen carrying capacity [19], however, this layer of loach was mainly composed of multi-layered swollen cells, which were bulky and vacuolated. Similar structures occurred in the middle layer of amphibious skin [35]. The multi-layered structure possibly played a role of a water-blocking barrier to keep the skin moist when exposed to the air for a long time [22]. In many fish species with cutaneous respiration, such as mudskipper (Periophthalmus cantonensis), abundant micro-vessels were also detected in the epidermis [35]. Two "trauma models" of skin resection in loach (cutaneous air-breathing fish) and yellow catfish (non-cutaneous air-breathing fish) were uniquely adopted in exploration to the mechanism of fish cutaneous accessory respiration. Based on the observation of histological structures, the capillaries appeared in the basal layer of the epidermis of original and regenerated skins to promote cutaneous air-breathing in loach. The well vascularized tissues/organs provided the structural basis for gas exchange.

After the cutaneous trauma occurs, it is repaired in three stages: inflammation, tissue formation, and tissue remodeling [36], among which angiogenesis and vascularization are important factors in wound healing [37]. The histological evidence indicated that the respiratory function of fish skin lies on the well vascularization in skin [35,38-40]. The original and regenerated skins of these two fish species were investigated by transcriptome analyses. A vast of genes were identified upon skin regeneration process, and abundant genes related to cellular differentiation, proliferation, growth, and development were activated to promote the completion of the regeneration of skins. In addition, the immune response was also activated since multiple immunity genes were up-regulated in the regenerated skins to resist the invasion of external bacteria or harmful substances.

In the present study, tens of genes and thirteen pathways that potentially associated with cutaneous air-breathing were identified in loach, by comparative transcriptome analyses of original and regenerated skins. Interleukins (itga5 and igta11), thrombospondins (thbs1, thbs2, and thbs $4 b$ ), and fibronectin ( $f n 1$ ) were up-regulated upon whole process of skin regeneration. Integrins, one of the important members of the cell adhesion molecule family, are a class of transmembrane glycoprotein receptors widely distributed on the cell surface. They mainly mediate the cell-to-cell interaction and extracellular matrix, and induce cellular proliferation, differentiation, migration, and survival of endothelial cells to promote angiogenesis [41,42]. The thrombospondins are mainly involved in embryonic 
development, wound healing, synaptogenesis, and tumor formation [43]. Previous studies have shown that thbs 1 can induce apoptosis of vascular endothelial cells by activating the CD36, P53, caspase-3, and p38-MAPK pathways [44]. Thbs1 can also prevent proangiogenic growth factors from binding to their receptors on the surface of endothelial cells while indirectly inhibiting angiogenesis [45]. Thbs2 can bind to CD36 and inhibit the migration of vascular endothelial cells and the formation of luminal cavity [46]. The thrombospondin members of thbs 1 , thbs 2 and thbs $4 b$ were up-regulated at $9^{\text {th }}$ daci in loach, which indicated that the vascular construction of regenerated skin was initially completed, consistent with the histological observation of regenerated skin. In addition, fibronectin plays a vital role in cell adhesion [47], blood vessel development, and heart morphogenesis both in zebrafish [48] and mouse [49,50]. fn1 was up-regulated in the regenerated skin of loach, which indicated a potential role of cutaneous air-breathing formation in loach, whereas the genes of $b m p 2$, chd, il11, wnt $9 b$ and $n f a t c 1$ were up-regulated at the initial stage of skin regeneration (3th and 6th daci). Bone morphogenetic protein (BMP) signaling has recently emerged as a fundamental pathway of the endothelium by regulating cardiovascular and lymphatic development and by being causative for several vascular dysfunctions [51]. It is reported that bmp2 can activate endothelial cells and significantly promote the sprouting and extension of vascular endothelial cells, thereby forming a blood vessel network [52]. Il11, a member of IL6 superfamily, has been found to have many physiological functions, such as stimulating red blood cell and platelet production [53]. Wnt signaling pathway family proteins are secreted glycoproteins that play an important role in embryonic development [54].

Considering the DEGs of regenerated skin of yellow catfish, we further screened out loxl2b, lgals1, and plekhh1, which were considered as the key candidate genes involved cutaneous air-breathing formation in loach. LOXL2, a prototypical lysyl oxidase, is implicated in the promotion of cancer cell invasion, metastasis and angiogenesis, as well as in the malignant transformation of solid tumors [55]. Loxl2 increases the expression level of vegf in cancer, while angiogenesis contributes to primary and metastatic cancer growth, and it is necessary for tumor progression [56,57]. A study on the effects of lox expression on tumor-driven angiogenesis, demonstrated that the regulation of mRNA and protein expression was carried out through the platelet-derived growth factor $\beta$ (PDGFR $\beta$ )-mediated activation of protein kinase B (Akt) [58]. Moreover, the inhibition of loxl2 activity inhibited angiogenesis in part by affecting VEGF signaling in endothelial cells [59] Lgals1/Galectin 1 is one of the members of galectin and plays multifaceted roles in cell adhesion, proliferation, angiogenesis, and immunosuppression, targeting not only a variety of cancer cells, but also vascular endothelial cells and regulatory T cells [60,61]. Lgals1 was reported to play a crucial role in promoting angiogenesis in anti-VEGF-A refractory tumors and was shown to interact with the N-glycans on Ig domains 3, 4, and 7 of vegfr2, causing increased phosphorylation of VEGFR2 and activation of its downstream signaling pathways in endothelial cells [62]. Anti-VEGF-A refractory tumors enhanced galectin-1 secretion together with its increased binding to neovascular endothelial cells due to altered glycosylation patterns on VEGFR2, leading to galectin-1-driven angiogenesis and tumor progression [63]. Plekhh1 is a number of pleckstrin homology domain superfamily, containing two predicted coiled-coil domains and a phosphositide-binding module called PH domain, as little has been known about this protein. [64,65]. Notably, fn1 also differentially expressed in yellow catfish, but the degree of significant difference was much less than that of loach. FN1 performs an important role in angiogenesis and development, and recent reports demonstrated the activation on Akt signaling pathway by binding with its receptor ITGA5, further activating mTOR pathway to regulate angiogenesis [66].

It is generally acknowledged that neovascularization mainly refers to the formation of blood vessels by the existing capillaries by germination, while angiogenesis mostly means the proliferation and differentiation of endothelial progenitor cells, turning into endothelial cells to form new blood vessels [67-69]. Actually, not only could micro-vessels provide adequate fresh blood with nutrient substances for inflammatory cells and stem 
cells necessary for wound repair [70], but also perform an indispensable role for aerial ventilation in loach of skin defect. Therefore, a reasonable speculation was put forward that there was a balance for blood angiogenesis and development during skin regeneration between promoting of tissue healing and maintaining the function of skin air-breathing in fishes with cutaneous respiration. Nevertheless, it is still to be examined what exact factors affecting this balance and its dynamic changes in the future exploration.

\section{Conclusions}

In the present study, we examined the skin regeneration of a cutaneous air-breathing loach M. anguillicaudatus and a water-breathing yellow catfish $P$. fulvidraco with respect to the morphological and histological observations and gene expression profiles. The capillaries embed in the basal layer of the epidermis of original and regenerated skins promote cutaneous air-breathing in fish, which provided the structural basis for gas exchange. Subsequently, the comparative transcriptomic analysis indicated that tens of genes and thirteen key pathways were strongly tied to cutaneous skin air-breathing in loach. This study provides substantial contribution to the molecular biology profiles of skin regeneration of fish, and, furthermore, offers new insights into the formation mechanism of cutaneous air-breathing in bimodal respiration fish.

Supplementary Materials: The following are available online at https:/ / www.mdpi.com/article/10.3 390/biology10121294/s1, Figure S1: Confirmation experiment of cutaneous air-breathing in loach. Figure S2: Detections of homologous genes in five public databases (Nr, Swiss-Prot, KEGG, KOG, and GO) for loach and yellow catfish. Figure S3: Network of KEGG pathways and target genes associated with cutaneous air-breathing formation in loach. Table S1: Primer sequences used in the present study for quantitative PCR (qPCR). Table S2: Differentially expressed genes in comparisons of RS/OS pertain of loach and yellow catfish. Table S3: Enriched GO items of DEGs in comparisons of RS/OS pertain of loach and yellow catfish. Table S4: Key GO items associated with cutaneous air-breathing formation in loach.

Author Contributions: Data curation, S.H. and B.S.; Formal analysis, L.H.; Funding acquisition, J.G. and X.C.; Investigation, S.H., B.S., L.Y., C.L. and J.Z.; Resources, L.H. and L.Y.; Software, S.H.; Supervision, J.G. and X.C.; Validation, S.H. and B.S.; Writing-original draft, S.H.; Writing-review and editing, J.G. and X.C. All authors have read and agreed to the published version of the manuscript.

Funding: This study was financially supported by the Fundamental Research Funds for the Central Universities of China (Project Number: 2662020SCPY002), Ministry of Agriculture and Rural Affairs of the People's Republic of China (Project Title: Conservation and proliferation of loach germplasm resources in the Yangtze River Basin, Project Number: 125C0505) and the National College Students Innovation and Entrepreneurship Training Program of China (Project Number: 202010504066).

Institutional Review Board Statement: The study was conducted according to the guidelines of the Care and Use of Laboratory Animals of Huazhong Agricultural University, Wuhan, China, and approved by the Animal Experimental Ethical Inspection of Laboratory Animal Center, Huazhong Agricultural University (Protocol code: HZAUFI-2021-0031, 1 December 2021).

Informed Consent Statement: Not applicable.

Data Availability Statement: All sequencing data are deposited in the DNA Data Bank of Japan (DDBJ) database under accession DRA012772.

Conflicts of Interest: The authors declare no conflict of interest.

\section{References}

1. Lefevre, S.; Bayley, M.; McKenzie, D.J.; Craig, J.F. Air-breathing fishes. J. Fish Biol. 2014, 84, 547-553. [CrossRef]

2. Damsgaard, C.; Baliga, V.B.; Bates, E.; Burggren, W.; McKenzie, D.J.; Taylor, E.; Wright, P.A. Evolutionary and cardiorespiratory physiology of air-breathing and amphibious fishes. Acta Physiol. 2020, 228, e13406. [CrossRef] [PubMed]

3. Kumar, D. Air-breathing organs and Nervous control of respiration in Freshwater fishes. Res. J. Sci. Technol. 2020, 12, 143. [CrossRef]

4. Park, J.Y.; Kim, I.S.; Kim, S.Y. Structure and mucous histochemistry of the intestinal respiratory tract of the mud loach, Misgurnus anguillicaudatus (Cantor). J. Appl. Ichthyol. 2003, 19, 215-219. [CrossRef] 
5. Singh, J.P.N.; Yadava, R.Y. Histopathological alterations in labyrinthine organ of an air breathing climbing perch Anabas testudineus exposed to 2,4 dichlorophenoxyacetic acid. J. Exp. Zool. India 2011, 14, 69-76.

6. Lefevre, S.; Wang, T.; Jensen, A.; Cong, N.V.; Huong, D.T.T.; Phuong, N.T.; Bayley, M. Air-breathing fishes in aquaculture. What can we learn from physiology? J. Fish Biol. 2014, 84, 705-731. [CrossRef] [PubMed]

7. Jiang, Y.; Feng, S.; Xu, J.; Zhang, S.; Li, S.; Sun, X.; Xu, P. Comparative transcriptome analysis between aquatic and aerial breathing organs of Channa argus to reveal the genetic basis underlying bimodal respiration. Mar. Genom. 2016, 29, 89-96. [CrossRef]

8. Xu, J.; Bian, C.; Chen, K.; Liu, G.; Jiang, Y.; Luo, Q.; You, X.; Peng, W.; Li, J.; Huang, Y. Draft genome of the Northern snake-head, Channa argus. Gigascience 2017, 6, gix011. [CrossRef]

9. Li, N.; Bao, L.; Zhou, T.; Yuan, Z.; Liu, S.; Dunham, R.; Li, Y.; Wang, K.; Xu, X.; Jin, Y.; et al. Genome sequence of walking catfish (Clarias batrachus) provides insights into terrestrial adaptation. BMC Genom. 2018, 19, 952. [CrossRef]

10. Luo, W.W.; Cao, X.J.; Xu, X.W.; Huang, S.Q.; Liu, C.S.; Tomljanovic, T. Developmental transcriptome analysis and identifica-tion of genes involved in formation of intestinal air-breathing function of Dojo loach, Misgurnus anguillicaudatus. Sci. Rep. 2016, 6, 31845. [CrossRef]

11. Huang, S.Q.; Cao, X.J.; Tian, X.C. Transcriptome analysis of compromise between air-breathing and nutrient uptake of posterior intestine in loach (Misgurnus anguillicaudatus), an air-breathing fish. Mar. Biotechnol. 2016, 18, 521-533. [CrossRef]

12. Huang, S.; Cao, X.; Tian, X.; Wang, W. High-throughput sequencing identifies microRNAs from posterior intestine of loach (Misgurnus anguillicaudatus) and their response to intestinal air-breathing inhibition. PLoS ONE 2016, 11, e0149123. [CrossRef]

13. Otrock, Z.K.; Mahfouz, R.A.R.; Makarem, J.A.; Shamseddine, A.I. Understanding the biology of angiogenesis: Review of the most important molecular mechanisms. Blood Cells Mol. Dis. 2007, 39, 212-220. [CrossRef] [PubMed]

14. Roy, S.; Patel, D.; Khanna, S.; Gordillo, G.M.; Biswas, S.; Friedman, A.; Sen, C.K. Transcriptome-wide analysis of blood vessels laser captured from human skin and chronic wound-edge tissue. Proc. Natl. Acad. Sci. USA 2007, 104, 14472-14477. [CrossRef] [PubMed]

15. Helbo, S.; Weber, R.E.; Fago, A. Expression patterns and adaptive functional diversity of vertebrate myoglobins. Biochim. Biophys. Acta (BBA) Proteins Proteom. 2013, 1834, 1832-1839. [CrossRef]

16. Feng, B.; Yi, S.V.; Li, R.W.; Zhou, X.Y. Comparison of age and growth performance of diploid and tetraploid loach Misgurnus anguillicaudatus in the Yangtze River basin, China. Environ. Biol. Fish. 2017, 100, 815-828. [CrossRef]

17. Zhang, H.P.; Chen, M.Y.; Xu, Y.X.; Xu, G.Y.; Chen, J.R.; Wang, Y.M.; Kang, Y.H.; Shan, X.F.; Kong, L.C.; Ma, H.X. An effective live attenuated vaccine against Aeromonas veronii infection in the loach (Misgurnus anguillicaudatus). Fish Shellfish. Immunol. 2020, 104, 269-278. [CrossRef]

18. Gonçalves, A.F.; Castro, L.F.; Pereira-Wilson, C.; Coimbra, J.; Wilson, J. Is there a compromise between nutrient uptake and gas exchange in the gut of Misgurnus anguillicaudatus, an intestinal air-breathing fish? Comp. Biochem. Physiol. Part D Genom. Proteom. 2007, 2, 345-355. [CrossRef]

19. Seo, E.; Yoon, G.Y.; Kim, H.N.; Lim, J.H.; Kim, S.; Kim, B.; Kim, K.H.; Lee, S.J. Morphological features of mucous secretory organ and mucous secretion of loach Misgurnus anguillicaudatus skin for friction drag reduction. J. Fish Biol. 2020, 96, 83-91. [CrossRef]

20. Park, J.Y.; Kim, I.S. Structure and histochemistry of skin of mud loach, Misgurnus anguillicaudatus (Pisces, Cobitidae), from Korea. Korean L. Ichthyol. 1999, 11, 109-116.

21. Park, J.; Kim, I.; Kim, S. Morphology and histochemistry of the skin of the mud loach, misgurnus mizolepis, in relation to cutaeneous respiration. Korean J. Biol. Sci. 2001, 5, 303-308. [CrossRef]

22. Yokoya, S.; Tamura, O.S. Fine structure of the skin of the amphibious fishes, Boleophthalmus pectinirostris and Periophthalmus cantonensis, with special reference to the location of blood vessels. J. Morphol. 1992, 214, 287-297. [CrossRef]

23. Wang, C.; Xie, S.; Zhu, X.; Lei, W.; Yang, Y.; Liu, J. Effects of age and dietary protein level on digestive enzyme activity and gene expression of Pelteobagrus fulvidraco larvae. Aquaculture 2006, 254, 554-562. [CrossRef]

24. Cao, X.J.; Wang, W.M. Histology and Mucin Histochemistry of The Digestive Tract of Yellow Catfish, Pelteobagrus fulvidraco. Anat. Histol. Embryol. 2009, 38, 254-261. [CrossRef]

25. Leclair, E.E.; Jacek, T.; Bruce, R. Development and regeneration of the zebrafish maxillary barbel: A novel study system for vertebrate tissue growth and repair. PLoS ONE 2010, 5, e8737. [CrossRef]

26. Grabherr, M.G.; Haas, B.J.; Yassour, M.; Levin, J.Z.; Thompson, D.A.; Amit, I.; Adiconis, X.; Fan, L.; Raychowdhury, R.; Zeng, Q.; et al. Full-length transcriptome assembly from RNA-Seq data without a reference genome. Nat. Biotechnol. $2011,29,644-652$. [CrossRef] [PubMed]

27. Deng, Y.Y.; Li, J.Q.; Wu, S.F.; Zhu, Y.; Chen, Y.W.; He, F.C. Integrated nr database in protein annotation system and its localization. Comput. Een. 2006, 32, 71-72.

28. Apweiler, R.; Bairoch, A.; Wu, C.H.; Barker, W.C.; Boeckmann, B.; Ferro, S.; Gasteiger, E.; Huang, H.Z.; Lopez, R.; Magrane, M. UniProt: The universal protein knowledgebase. Nucleic Acids Res. 2004, 32, 115-119. [CrossRef]

29. Ashburner, M.; Ball, C.A.; Blake, J.A.; Botstein, D.; Butler, H.; Cherry, J.M.; Davis, A.P.; Dolinski, K.; Dwight, S.S.; Eppig, J.T.; et al. Gene ontology: Tool for the unification of biology. The Gene Ontology Consortium. Nat. Genet. 2000, 25, 25-29. [CrossRef]

30. Tatusov, R.L.; Galperin, M.; Natale, D.A.; Koonin, E.V. The COG database: A tool for genome-scale analysis of protein functions and evolution. Nucleic Acids Res. 2000, 28, 33-36. [CrossRef] [PubMed]

31. Kanehisa, M.; Goto, S.; Kawashima, S.; Okuno, Y.; Hattori, M. The KEGG resource for deciphering the genome. Nucleic Acids Res. 2004, 32, D277-D280. [CrossRef] 
32. Trapnell, C.; Williams, B.A.; Pertea, G.; Ali, M.; Kwan, G.; Baren, M.J.; Salzberg, S.L.; Wold, B.J.; Pachter, L. Transcript assembly and quantification by RNA-Seq reveals unannotated transcripts and isoform switching during cell differentiation. Nat. Biotechnol. 2010, 28, 511-515. [CrossRef]

33. Anders, S.; Huber, W. Differential expression analysis for sequence count data. Genome. Biol. 2010, 11, R106. [CrossRef]

34. Livak, K.J.; Schmittgen, T.D. Analysis of Relative Gene Expression Data Using Real-Time Quantitative PCR and the $2^{-\Delta \Delta C T}$ Method. Methods 2001, 25, 402-408. [CrossRef]

35. Beon, M.S.; Oh, M.K.; Lee, Y.J.; Kim, C.H.; Park, J.Y. A comparative study on vascularization and the structure of the epidermis of an amphibious mudskipper fish, Scartelaos gigas (Gobiidae, Teleostei), on different parts of the body and the appendages. J. Appl. Ichthyol. 2013, 29, 6. [CrossRef]

36. Singer, A.J.; Clark, R.A. Cutaneous wound healing. N. Engl. J. Med. 1999, 341, 738-746. [CrossRef]

37. Sheng, L.; Yang, M.; Liang, Y.; Li, Q. Adipose tissue-derived stem cells (ADSCs) transplantation promotes regeneration of expanded skin using a tissue expansion model. Wound Repair Regen. 2013, 21, 746-754. [CrossRef] [PubMed]

38. André, L.C.; Prado, T.M.; Laísa, P.R.; Wilfried, K. The potential respiratory surfaces of a fish living in a historically polluted river. Anim. Biol. 2019, 70, 101-108.

39. Zhang, J.; Taniguchi, T.; Takita, T.; Ali, A.B. A study on the epidermal structure of Periophthalmodon and Periophthalmus mudskippers with reference to their terrestrial adaptation. Ichthyol. Res. 2003, 50, 310-317. [CrossRef]

40. Park, J.Y.; Kim, I.S.; Lee, Y.J. A study on the vascularization and structure of the epidermis of the air-breathing mudskipper, Periophthalmus magnuspinnatus (Gobiidae, Teleostei), along different parts of the body. J. Appl. Ichthyol. 2006, 22, 62-67. [CrossRef]

41. Silvestre, J.S.; Théry, C.; Hamard, G.; Boddaert, J.; Aguilar, B.; Delcayre, A.; Houbron, C.; Tamarat, R.; Blanc-Brude, O.; Heeneman, S.; et al. Lactadherin promotes VEGF-dependent neovascularization. Nat. Med. 2005, 11, 499-506. [CrossRef]

42. Wang, J.; Yang, L.; Liang, F.; Chen, Y.; Yang, G. Integrin alpha x stimulates cancer angiogenesis through PI3K/Akt signaling mediated VEGFR2/VEGF-A overexpression in blood vessel endothelial cells. J. Cell. Biochem. 2019, 120, 1807-1818. [CrossRef] [PubMed]

43. Chen, H.; Herndon, M.E.; Lawler, J. The cell biology of thrombospondin-1. Matrix. Biol. 2000, 19, 597-614. [CrossRef]

44. Koch, W.; Hoppmann, P.; De Waha, A.; Schömig, A.; Kastrati, A. Polymorphisms in thrombospondin genes and myocardial infarction: A case-control study and a meta-analysis of available evidence. Hum. Mol. Genet. 2008, 17, 1120-1126. [CrossRef] [PubMed]

45. Hauser, N.; Paulsson, M.; Kale, A.A.; Dicesare, P.E. Tendon extracellular matrix contains pentameric thrombospondin-4 (TSP4). FEBS Lett. 1995, 368, 307-310. [CrossRef]

46. Zhang, J.; Ito, R.; Oue, N.; Zhu, X.; Kitadai, Y.; Yoshida, K.; Nakayama, H.; Yasui, W. Expression of thrombospondin-1 is correlated with microvessel density in gastric carcinoma. Virchows Arch. 2003, 442, 563-568. [CrossRef]

47. Hsiao, C.T.; Cheng, H.W.; Huang, C.M.; Li, H.R.; Ou, M.H.; Huang, J.R.; Khoo, K.H.; Yu, H.W.; Chen, Y.; Wang, Y.K.; et al. Fibronectin in cell adhesion and migration via N-glycosylation. Oncotarget 2017, 8, 70653-70668. [CrossRef]

48. Le, A.T.; Stainier, D. Fibronectin regulates epithelial organization during myocardial migration in zebrafish. Dev. Cell 2004, 6, 371-382. [CrossRef]

49. Wijelath, E.S.; Murray, J.; Rahman, S.; Patel, Y.; Ishida, A.; Strand, K.; Aziz, S.; Cardona, C.; Hammond, W.P.; Savidge, G.F.; et al. Novel vascular endothelial growth factor binding domains of fibronectin enhance vascular endothelial growth factor biological activity. Circ. Res. 2002, 91, 25-31. [CrossRef] [PubMed]

50. George, E.L.; Baldwin, H.S.; Hynes, R.O. Fibronectins are essential for heart and blood vessel morphogenesis but are dispensable for initial specification of precursor cells. Blood 1997, 90, 3073-3081. [CrossRef]

51. de Vinuesa, A.G.; Abdelilah-Seyfried, S.; Knaus, P.; Zwijsen, A.; Bailly, S. BMP signaling in vascular biology and dysfunction. Cytokine Growth Factor Rev. 2016, 27, 65-79. [CrossRef]

52. Benn, A.; Hiepen, C.; Osterland, M.; Schütte, C.; Zwijsen, A.; Knaus, P. Role of bone morphogenetic proteins in sprouting angiogenesis: Differential BMP receptor-dependent signaling pathways balance stalk vs. tip cell competence. FASEB J. 2017, 31, 4720-4733. [CrossRef]

53. Garbers, C.; Hermanns, H.M.; Schaper, F.; Müller-Newen, G.; Grötzinger, J.; Rose-John, S.; Scheller, J. Plasticity and cross-talk of Interleukin 6-type cytokines. Cytokine Growth Factor Rev. 2012, 23, 85-97. [CrossRef]

54. van Loon, K.; Huijbers, E.J.M.; Griffioen, A.W. Secreted frizzled-related protein 2: A key player in noncanonical Wnt signaling and tumor angiogenesis. Cancer Metastasis Rev. 2021, 40, 191-203. [CrossRef]

55. Wu, L.; Zhu, Y. The function and mechanisms of action of LOXL2 in cancer. Int. J. Mol. Med. 2015, 36, 1200-1204. [CrossRef]

56. Ferrara, N.; Kerbel, R.S. Angiogenesis as a therapeutic target. Nat. Cell Biol. 2005, 438, 967-974. [CrossRef]

57. Kerbel, R.S. Tumor angiogenesis. N. Engl. J. Med. 2008, 358, 2039-2049. [CrossRef] [PubMed]

58. Baker, A.M.; Bird, D.; Welti, J.; Gourlaouen, M.; Lang, G.; Murray, G.I.; Reynolds, A.R.; Cox, T.R.; Erler, J.T. Lysyl oxidase plays a critical role in endothelial cell stimulation to drive tumor angiogenesis. Cancer Res. 2013, 73, 583-594. [CrossRef] [PubMed]

59. Zaffryar Eilot, S.; Marshall, D.; Voloshin, T.; Bar Zion, A.; Spangler, R.; Kessler, O.; Ghermazien, H.; Brekhman, V.; Suss Toby, E.; Adam, D. Lysyl oxidase-like-2 promotes tumour angiogenesis and is a potential therapeutic target in angiogenic tumours. Carcinogenesis 2013, 34, 2370-2379. [CrossRef] [PubMed]

60. Thijssen, V.L.; Poirier, F.; Baum, L.G.; Griffioen, A.W. Galectins in the tumor endothelium: Opportunities for combined cancer therapy. Blood 2007, 110, 819-2827. [CrossRef] [PubMed] 
61. Zhao, X.Y.; Chen, T.T.; Xia, L.; Guo, M.; Xu, Y.; Yue, F.; Jiang, Y.; Chen, G.Q.; Zhao, K.W. Hypoxia inducible factor-1 mediates expression of galectin-1: The potential role in migration/invasion of colorectal cancer cells. Carcinogenesis 2010, 31, 1367-1375. [CrossRef] [PubMed]

62. Croci, D.O.; Cerliani, J.P.; Dalotto-Moreno, T.; Méndez-Huergo, S.P.; Mascanfroni, I.D.; Dergan-Dylon, S.; Toscano, M.; Caramelo, J.J.; García-Vallejo, J.J.; Ouyang, J.; et al. Glycosylation-dependent lectin-receptor interactions preserve angiogenesis in anti-VEGF refractory tumors. Cell 2014, 156, 744-758. [CrossRef] [PubMed]

63. Kanda, A.; Noda, K.; Saito, W.; Ishida, S. Aflibercept traps Galectin-1, an angiogenic factor associated with diabetic retinopathy. Sci. Rep. 2016, 5, 17946. [CrossRef] [PubMed]

64. Lenoir, M.; Kufareva, I.; Abagyan, R.; Overduin, M. Membrane and protein interactions of the Pleckstrin homology domain superfamily. Membranes 2015, 5, 646-663. [CrossRef] [PubMed]

65. Chao, T.; Zhou, X.; Cao, B.; Liao, P.; Liu, H.B.; Chen, Y.; Park, H.W.; Zeng, S.X.; Lu, H. Pleckstrin homology domain containing protein PHLDB3 supports cancer growth via a negative feedback loop involving p53. Nat. Commun. 2016, 7, 13755. [CrossRef]

66. Mana, G.; Clapero, F.; Panieri, E.; Panero, V.; Böttcher, R.T.; Tseng, H.Y.; Saltarin, F.; Astanina, E.; Wolanska, K.I.; Morgan, M.; et al. PPFIA1 drives active $\alpha 5 \beta 1$ integrin recycling and controls fibronectin fibrillogenesis and vascular morphogenesis. Nat. Commun. 2016, 7, 13546. [CrossRef] [PubMed]

67. Martin, P. Wound Healing-Aiming for Perfect Skin Regeneration. Science 1997, 276, 75-81. [CrossRef] [PubMed]

68. Kampfer, H.; Pfeilschifter, J.; Frank, S. Expressional regulation of angiopoietin-1 and -2 and the tie-1 and -2 receptor tyrosine kinases during cutaneous wound healing: A comparative study of normal and impaired repair. Lab. Investig. 2001, 81, 361-373. [CrossRef]

69. Usui, M.L.; Mansbridge, J.N.; Carter, W.G.; Fujita, M.; Olerud, J.E. Keratinocyte Migration, Proliferation, and Differentiation in Chronic Ulcers From Patients With Diabetes and Normal Wounds. J. Histochem. Cytochem. 2008, 56, 687-696. [CrossRef] [PubMed]

70. Sheng, L.; Yang, M.; Li, H.; Du, Z.; Yang, Y.; Li, Q. Transplantation of adipose stromal cells promotes neovascularization of random skin flaps. Tohoku J. Exp. Med. 2011, 224, 229-234. [CrossRef] 